\title{
Ensinando zoologia a partir da letra da música "Tico-tico no fubá”, de Zequinha de Abreu
}

\section{Zoology teaching using the lyrics of the music "Tico-tico no fubá" by Zequinha de Abreu}

\author{
${ }^{1}$ Lucas de Esquivel Dias Brandão lucasdesquivel@hotmail.com \\ ${ }^{1}$ Jéssica Gontijo Andrade \\ ${ }^{1}$ Diego Victor Cerqueira Dias \\ ${ }^{2}$ Marcelo Diniz Monteiro de Barros
}

\section{RESUMO}

Nas disciplinas de Ciências e Biologia não é comum a utilização da música como estratégia de ensino. Porém, para a disciplina de História, não é raro encontrar em obras didáticas letras de música popular ilustrando determinados conteúdos conceituais. Visando contribuir para a melhoria no modo como o ensino é realizado nas escolas de educação básica, o presente estudo desenvolveu uma atividade contendo 9 questões sobre a música "Tico-tico no fubá”, de Zequinha de Abreu, que pode ser trabalhada nas disciplinas de Ciências e Biologia. Espera-se que os professores de Ciências e Biologia tenham acesso a essa atividade e que possam, de acordo com os seus anseios, trabalhar os diferentes conteúdos biológicos que se fazem presentes na letra da música. Pretende-se, ainda, despertar a criatividade dos professores, de forma que os mesmos possam desenvolver outras atividades como essa, em suas práticas educativas.

Palavras-chave: Ensino de Ciências e Biologia; Música como estratégia de Ensino; Tico-tico no fubá.

\section{ABSTRACT}

In the Science and Biology disciplines, it is not common to use music as a teaching strategy. However, for the discipline of history, it is not rare to find in textbooks popular lyrics illustrating certain conceptual contents. Aiming to contribute to the improvement in the way teaching is done in schools, this study developed an activity containing 10 questions about the song "Tico-Tico no fubá" of Zequinha de Abreu, which can be worked in Science and Biology disciplines. It is expected that the Science and Biology teachers have access to this activity and can, according to their desires, work the different biological contents that are present in the lyrics. It is intended, also, to awaken the creativity of teachers, so that they can develop other activities like this in their educational practices.

Key word: Science and Biology teaching; Music as a Teaching Strategy; Tico-tico no fubá.

1 Departamento de Ciências Biológicas da Pontifícia Universidade Católica de Minas Gerais, PUC Minas.

2 Professor Colaborador do Programa de Pós-Graduação em Ensino em Biociências e Saúde do Instituto Oswaldo Cruz, Fiocruz, no Rio de Janeiro. Professor adjunto IV do Departamento de Ciências Biológicas da PUC Minas. 


\section{INTRODUÇÃO}

A música ocupava uma posição de destaque em toda a antiguidade. Era uma disciplina obrigatória nos currículos básicos (BARROS, ZANELLA e ARAÚJO-JORGE, 2013). Desde o século XVI, no Brasil, os jesuítas já utilizavam a música como atrativo nos seus ideais de catequização (BOLEIZ JÚNIOR, 2008). Porém, atualmente, o desaparecimento gradual da música na escola demonstra, de alguma maneira, uma crescente desvalorização desse conhecimento pela sociedade.

As músicas fazem parte do cotidiano, traduzindo sentimentos, situações, informações acerca dos seres vivos, dos processos científicos e dos espaços em que vivemos. Pode-se observar que o campo das formas musicais é verdadeiramente fértil e de fácil assimilação, portanto, útil para o trabalho do professor que deseja renovar, dinamizar e buscar maior eficiência de aprendizado em seu modo de explicar a matéria (FERREIRA, 2008).

Muitas são as vantagens para a utilização da música como recurso didático- pedagógico em aulas de Ciências: é uma alternativa de baixo custo, uma oportunidade para o aluno estabelecer relações interdisciplinares, uma atividade lúdica que ultrapassa a barreira da educação formal e que chega à categoria de atividade cultural.

Nas disciplinas de Ciências e Biologia, não é comum a utilização da música como estratégia de ensino. Porém, para a disciplina de História, há uma pesquisa que registra que não é raro encontrar em obras didáticas letras de música popular ilustrando determinados conteúdos conceituais (ABUD, 2005).

O conhecimento biológico deve ser implementado de forma interdisciplinar e contextualizada, o que pode proporcionar uma menor utilização da memória e um maior aproveitamento do raciocínio. Desse modo, analisar os conteúdos conforme o contexto é um importante recurso capaz de retirar o estudante da condição de espectador passivo, permitindo uma aprendizagem mais significativa (MARTINS et. al, 2014; SILVA et. al, 2013).

Portanto, o presente estudo, visando contribuir para a melhoria no modo como o ensino é realizado nas escolas de educação básica atualmente, acredita que a música pode ser utilizada como uma ferramenta eficiente capaz de contextualizar, e desse modo, facilitar a aquisição do conteúdo biológico pelos alunos. Assim, apresentamos uma forma de se utilizar a canção "Tico-tico no fubá" como uma alternativa para promover o ensino de Ciências e Biologia.

\section{METODOLOGIA}

Foi desenvolvida uma atividade contendo 9 questões, sobre a música "Tico-tico no fubá" de Zequinha de Abreu, que pode ser trabalhada nas disciplinas de Ciências e Biologia. É necessário que os docentes testem a eficácia da atividade, em seus diferentes contextos educacionais, e que, se acharem necessário, efetuem modificações na mesma visando aproximar ainda mais o ensino de Ciências e Biologia da música popular brasileira. 


\section{RESULTADOS}

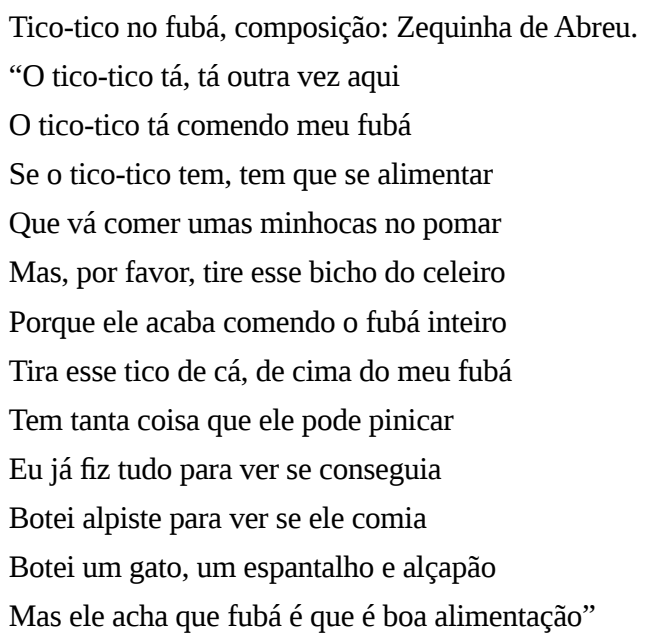

Perguntas propostas:

1. O pássaro conhecido como Tico-tico, retratado na música cantada por Leci Brandão, ABREU (2010), é uma ave muito conhecida e estimada no Brasil. Liste alguns outros nomes populares conhecidos para esses indivíduos nas diferentes regiões brasileiras.

Sugestão de resposta: “salta-caminho” (Pernambuco e interior da Paraíba), titiquinha e ticão, gitica, mariquita-tio-tio (São Paulo), tiquinho (Paraná), catete (Bahia), toinho (Paraíba - Região do Seridó Ocidental) e piqui-meu-deus (sul do Ceará) (DIAS, 2015).

2. A festa junina é uma das manifestações mais tradicionais do Nordeste e acontece em todos os Estados brasileiros. Além das danças e música típica, um dos maiores atrativos são os quitutes tipicamente servidos na festa. Trata-se de uma culinária rica em ingredientes multiculturais e em criatividade. Na música foi mencionado o fubá, que pode ser feito por meio do milho moído ou do arroz. Classifique o milho, quanto à classe (monocotiledônea ou eudicotiledônea) e ao tipo de reprodução vegetal. Indique a qual família pertence o arroz, dê exemplos de outras plantas que fazem parte dessa família e explique como o arroz foi introduzido no Brasil.

Sugestão de resposta: O milho pertence a classe monocotiledônea e exibe reprodução sexuada (UZUNIAN e BIRNER, 2008). O arroz é uma planta da família das gramíneas (Poaceae), da qual fazem parte o trigo, a cevada, o centeio e a aveia, e foi introduzido no país no século XVI, nos primórdios do Brasil Colônia, vindo provavelmente de Cabo Verde.

Baseando-se no trecho da música: "Se o tico-tico tem, tem que se alimentar/ Que vá comer umas minhocas no pomar”, responda as seguintes questões.

3. Discorra sobre o hábito alimentar do Tico-tico.

Sugestão de resposta: Alimenta-se de sementes, brotos, frutas e insetos, como por exemplo besouros, formigas, grilos, cupins alados e larvas. Costuma frequentar comedouros com sementes e quirera de milho, sendo também visto, comendo ração para cães (DIAS, 2015). 
4. Descreva a importância das minhocas para o solo.

Sugestão de resposta: As minhocas são muito úteis para o funcionamento do solo e a manutenção da sustentabilidade dos ecossistemas. Estes organismos são responsáveis pela melhoria da estrutura do solo e de sua qualidade física, através da movimentação de partículas dentro e entre os horizontes, pela formação de agregados e consequente aumento da resistência do solo à erosão, além de promover melhorias na porosidade, aeração, infiltração e retenção de água no solo. Através da formação de bioporos, facilitam a aeração, infiltração de água e a formação de macroagregados estáveis no solo. Participam da decomposição da matéria orgânica, da mineralização de nutrientes e da disponibilização destes elementos para as plantas, sendo por isso, sua presença considerada indicativo de solo fértil e saudável pelos agricultores. A atividade das minhocas no solo, mais especificamente a movimentação e ingestão de partículas minerais e orgânicas, forma uma ampla rede de galerias, tanto na direção vertical como na horizontal, que contribui para os processos físicos e para a manutenção da vida no solo. A abertura de galerias no perfil do solo, além de contribuir para a infiltração de água e troca de gases, quando não mais utilizadas pelas minhocas, servem de abrigo a outros organismos (STEFFEN et al., 2013).

5. A música cita o alpiste como possível alimento do tico-tico. Descreva alguns benefícios dessa planta para a saúde humana.

Sugestão de resposta: 1) O alpiste pode ajudar no tratamento do colesterol, auxiliando no emagrecimento e no ganho de massa muscular. 2) Trata a cirrose, controlando os hepatócitos do fígado, desinflamando-os. 3) Age eliminando o excesso de líquidos no nosso corpo, recarregando os rins com enzimas importantes ao seu correto funcionamento. 4) Por conter lipase, ele elimina com rapidez a gordura do organismo, tanto das veias e artérias, como também dos depósitos (culotes, barriga, braços, etc.) (OLIVEIRA, 2015).

6. “Desde que o ser humano se dedicou ao cultivo da terra, os pássaros foram os grandes inimigos das semeaduras e das colheitas. Seus ataques poderiam levar uma família à morte pela fome, durante o inverno. Para livrar-se dessa catástrofe, os lavradores começaram a idealizar, confeccionar e pôr em prática espantalhos, homens ou crianças vigiando os campos e espantando os pássaros, ou engenhocas de formas diversas, através dos tempos.” Tente fazer uma análise histórica sobre o porque os espantalhos dominaram tanto o imaginário popular mundial.

Sugestão de resposta: Criados para afugentar as aves e mamíferos que atacam as plantações, os espantalhos tornaram-se aliados dos agricultores minimizando os danos desses animais à plantação. É importante salientar que a forma dos espantalhos ou a maneira como eles são confeccionados pode variar conforme o lugar. Entre os materiais usados na confecção estão: vassouras, roupas velhas, chapéus de palha, entre outros. Por apresentarem uma feição deformada de um humano, muitas pessoas tinham medo desses bonecos de palha. Assim, os espantalhos ganharam a mente das pessoas por causa das lendas e histórias de terror que foram inventadas sobre eles, geralmente envolvendo magia negra, estigmatizando esses bonecos. Com o tempo, os espantalhos ganharam espaço no mundo das artes. Na literatura estavam inseridos em poemas e textos teatrais; nas telas do cinema, como protagonistas de histórias macabras em filmes e em séries (FARIAS, 2010). Cândido Portinari foi grandemente influenciado pela temática dos espantalhos. Uma busca ao acervo feita no site $<$ www.portinari.org. br> revelou mais de 100 obras de Portinari com o título "Espantalho" ou contendo essa palavra.

\section{Porque o aumento dos impactos ambientais pode afetar a abundância de minhocas em seu habitat natural?}

Sugestão de resposta: Com a atual escassez de chuvas e diminuição do nível dos rios, o solo tem ficado seco por mais tempo, principalmente em sua superfície. Uma vez que as minhocas não suportam viver em ambientes secos e iluminados, elas então procuram ficar abrigadas em galerias (feitas por elas mesmas) nas partes mais profundas do solo (RUPPERT; FOX e BARNES, 2005). Sendo assim, animais como o tico-tico terão muita dificuldade para encontrá-las na superfície do solo nos pomares. No entanto, se o pomar possuir muita matéria 
orgânica disposta sobre o solo (folhas caídas, palha) e este não for revolvido com frequência, é possível encontrar minhocas por ali (SCHIEDECK e SCHIAVON, 2009).

8. Porque o tico-tico na música demonstrou tanto interesse pelo celeiro?

Sugestão de resposta: Porque o celeiro é um local protegido onde se guardam os alimentos. O tico-tico provavelmente escolheu o celeiro por servir de abrigo para ele (do sol e de predadores) além de conter alimento disponível com facilidade (o fubá estocado), que pode ser considerado como um oásis para um faminto (e preguiçoso) tico-tico.

9. Quais são as tantas coisas que o tico-tico pode pinicar?

Sugestão de resposta: Vários itens alimentares, como sementes, frutos, insetos (SANTIAGO, 2008).

\section{DISCUSSÃO}

Belisário et al. (2013) demonstraram como contextualizar os conteúdos de botânica e história através da música “Tanto Mar”, de Chico Buarque (1978). Por meio dessa música, os professores de Biologia e de História, da educação básica, podem pedir aos seus alunos que procurem se aprofundar na temática do Dia da Liberdade; que caracterizem o período conhecido como a Primavera Marcelista; que investiguem um movimento popular, que tenha ocorrido em Portugal ou no Brasil, e descrevam seus aspectos mais importantes; podem também explicar a importância do embrião de uma planta para o seu estabelecimento na terra. Da mesma maneira, podem solicitar aos estudantes que representem o ciclo reprodutivo de uma fanerógama, identificando a fase gametofítica e a esporofítica; que elaborem um texto destacando o valor das algas, de maneira ampla, associando as mesmas ao mar; que façam uma reflexão sobre a importância das plantas e partes das mesmas no nosso dia a dia, nas nossas conquistas, na manutenção da biodiversidade, na manutenção da vida; dentre outros aspectos possíveis de se explorar na letra da música.

Brandão et al. (2014) mostraram como estudar botânica através da música "Feira de Mangaio” escrita por Sivuca e Glorinha Gadelha (1979). Trata-se de um clássico da música nordestina, que apresenta os produtos que são comercializados pelos mangaieiros nas feiras livres, que podem ser entendidas como verdadeiros celeiros culturais. Evidencia, ainda, as manifestações artísticas que compõem o modo de vida das pessoas que transitam por estas feiras. Através da canção, recomenda-se que os professores de Ciências, das séries finais do Ensino Fundamental, e Biologia, do Ensino Médio, possam trabalhar com os alunos a associação entre as culturas fumageira e tabagista e a saúde humana; que possam associar o milho, o amendoim, a cana de açúcar e o coco verde, às suas respectivas classes vegetais e aos diferentes tipos de reprodução; que possam compreender a interação existente entre plantas e aves e sua importância para a botânica; que aprendam e discutam o significado das diferentes expressões nordestinas; que entendam a importância das feiras de mangaio para o sustento das famílias nordestinas, entre outros aspectos retratados pela rica letra da música.

Brandão et al. (2016) registram como é possível aproximar os conteúdos botânicos para os alunos através da música “Espatódea”, escrita por Nando Reis em homenagem a sua filha Zoé. Através dessa música, sugere-se que o professor trabalhe com os alunos a relação entre a distribuição geográfica da Spathodea campanulata (P. Beauv) e os usos medicinais desta planta em cada região; as prováveis consequências que essa espécie vegetal pode provocar nas áreas onde foi introduzida; os nomes populares para a Espatódea; o motivo de a árvore ser conhecida como xixi de macaco; informações botânicas importantes como: tipo de inflorescência, tipo de fruto, função das flores na ornitofilia, nomes de componentes florais e suas respectivas funções, pigmentos responsáveis pelas cores vermelhas, laranjas e raramente amareladas das flores. A letra da música foi ricamente explorada, por exemplo no sentido de questionar o aluno sobre o órgão reprodutor que o gineceu representa e quais os diferentes recursos de atração adotados pelas flores, a partir da estrofe “Espatódea, gineceu cor de pólen”. Os 
discentes também podem criar grupos de discussão e propor hipóteses para explicar a toxicidade do néctar da planta; dentre outros.

Barros, Diniz e Araújo-Jorge (2014a) revelam como usar músicas na sala de aula para discutir temas de Ciências. Através de algumas músicas, como por exemplo a música de Gilberto Gil e Arnaldo Antunes intitulada "A ciência em si”, pode-se instigar reflexões sobre: que palavras e ideias chamam a atenção após a escuta da música e a leitura da letra; o que é lenda, o que é crença, o que é mito, o que é ciência; existe coincidência na ciência, o que é o acaso nos processos da vida; a música apresenta procedimentos de ciência, e de arte; aonde se quer chegar com a ciência, do que se quer despertar na ciência, o que seria um sono eterno. Os autores, mostram também, como utilizar a música "Ciência e Arte”, interpretada por Cartola, para se discutir Ciência. Algumas questões propostas para a discussão são: quem foram Pedro Américo e Cesar Lattes, como se pode saber; o que seria o Brasil de toda parte; o que significa panteon, e o panteon dos grandes imortais; quem pode ser sábio; o que é epopeia, quais são as possíveis epopeias triunfais de que nos fala a música, dentre outras discussões possíveis.

Através da música "Emergindo da Ciência”, cantada por Arnaldo Baptista, pode-se questionar o que significa pastar na vida; se existem semelhanças e diferenças entre o entretenimento e o envolvimento; o que o “jardim do sol” pode representar; o que pode emergir da ciência, pode-se também questionar se algo pode submergir (BARROS, DINIZ e ARAÚJO-JORGE, 2014a). E por fim, utilizando a poesia “Quanta”, interpretada por Gilberto Gil, pode-se indagar em quais aspectos a Arte é irmã da Ciência, ou se elas poderiam ter algum outro parentesco; como é formado o corpo da flor; o que são urânio e rádio, que características os tornam diferentes de outros elementos; no que qualidade e quantidade são diferentes; como as medições podem ser importantes para a ciência, se existem diferenças entre vento de calor e outros ventos, o que é o vento; descoberta e invenção são iguais ou diferentes; como relacionar o cântico dos cânticos com o quântico dos quânticos, etc. (BARROS, DINIZ e ARAÚJO-JORGE, 2014a).

Barros, Diniz e Araújo-Jorge (2014b), sugerem utilizar a música "Haiti”, interpretada por Caetano Veloso e Gilberto Gil, para se discutir situações de vulnerabilidade social. Através dessa música pode-se trabalhar com os alunos sobre: como é abordada a questão do racismo na música; se o deslumbramento e a grandeza épica de um povo em formação podem justificar a escravidão; o que representa o saco de lixo brilhante do Leblon; como se tratam os pretos, e os povos indígenas, e as mulheres, e os pobres; por que será que os presos são quase todos pretos, dentre outras questões possíveis de se levantar. Para a música "Caviar”, cantada por Zeca Pagodinho, sugere-se trabalhar as seguintes questões: por que quem come caviar e olha para o lado pode se deparar com a fome; qual é a diferença entre a fome de quem come caviar e a fome de quem não tem acesso a ele; o que é ter bala na agulha, o que significa a palavra iguaria, você pode indicar algumas delas; você pode diferenciar o valor comercial do caviar e do muçum; o pescar na vala pode trazer algum comprometimento para a saúde; dentre outras discussões possíveis.

Para a poesia “O Meu Guri”, interpretada por Chico Buarque, propõe-se debater: Por que será que não era o momento do rebento rebentar; o que significa chegar lá; de onde vem os presentes trazidos pelo menino para a mãe; como o guri saiu no jornal, o que isso significa; o que a mãe do menino quer dizer com "chegar cá no alto; etc. Para a canção "Burguesinha”, cantada por Seu Jorge, foram apresentadas as seguintes questões: o que é um burguês; a burguesinha aparece em algum momento trabalhando; de onde provavelmente vem o seu dinheiro; esse tipo de vida está de acordo com a realidade da maior parte do povo brasileiro; o que significa a tribo, dentre outros (BARROS, DINIZ e ARAÚJO-JORGE, 2014b).

Ainda de acordo com os mesmos autores, para a música "Miséria”, interpretada por Arnaldo Antunes, Sérgio Britto, e Paulo Miklos, objetiva-se indagar sobre: por que a miséria é sempre igual; todos sabem usar os dentes, mas como e com que são usados; a morte é a mais provável das consequências da miséria e por isso não causa mais espanto; alguém sabe falar esperanto; e português; e inglês; e outras línguas; os fracos, doentes, aflitos e carentes podem ter esperanças, Devem?. Já para a poesia "Pobreza por pobreza”, interpretada por Luiz 
Gonzaga, pergunta-se: por que o sertão está se acabando; gente boa está indo embora... por que isso acontece; "Pra que me largar no mundo se nem sei se vou chegar", quais as dificuldades que podem ser encontradas no caminho; onde o espinho pode dar; qual é a mão que vive a explorar; ser pobre é a mesma coisa em qualquer lugar; o que mais desespera, além da fome. E por fim, através da canção "Problema social”, cantada por Seu Jorge, recomenda-se trabalhar: O que é ser um peregrino; uma pessoa pode mudar a sua realidade; é possível ser um intelectual sem ter estudado em colégio legal; o que é o apoio moral retratado na música, ele poderia ter mudado a situação do menino; por que a Funabem é a morada de muitos, e como ela influencia na formação dessas pessoas (BARROS, DINIZ e ARAÚJO-JORGE, 2014b).

O Ensino de Ciências e de Biologia na atualidade é praticado, na maioria das vezes, através da pura transmissão de informações, sem que os alunos possam processá-las e interpretá-las corretamente. A variedade de conceitos existentes na biologia acaba gerando desinteresse nos estudantes, que passam a decorar os conteúdos sem estabelecer nenhuma relação do mesmo com o contexto em que vivem. É preciso então aprimorar essa metodologia tradicional de ensino em que o conhecimento é repassado ao aluno somente como informação, sem se preocupar se ocorreu de fato aprendizagem ou não (GIASSI e MORAES, 2007; SOBRINHO, 2009).

É essencial que os professores procurem inovar suas metodologias de ensino, buscando sempre contextualizar os diferentes assuntos, introduzindo alguns elementos inéditos e conservando alguns dos tradicionais, para evitar que suas disciplinas sejam meramente descritivas e desconectadas da realidade de seus alunos (SILVA et. al, 2009).

Portanto o objetivo principal de se utilizar letras de músicas para se ensinar Ciências na escola é o de viabilizar o desenvolvimento de oficinas e experimentos participativos e interativos entre os alunos, estimulando a criatividade dos mesmos para a arte e a ciência, permitindo que os mesmos observem, imaginem, abstraiam, reconheçam e formem padrões, de uma forma lúdica e interativa.

Espera-se que os professores de Ciências e Biologia tenham acesso a essa atividade e que possam, de acordo com os seus anseios, trabalhar os diferentes conteúdos biológicos que se fazem presentes na letra da música "Tico-tico no fubá". Pretende-se, ainda, despertar a criatividade dos professores, de forma que os mesmos possam desenvolver outras atividades como essa, em suas práticas educativas.

As vantagens de trabalhar os conteúdos aqui propostos com a música é o de promover uma atividade lúdica para os alunos, que proporcione um estado agradável de bem estar (BARROS, DINIZ e ARAÚJO-JORGE, 2016). Além disso, essa metodologia possibilita uma mudança na perspectiva do aluno, que agora pode aprimorar suas competências e habilidades, como por exemplo, obter uma maior sensibilidade, criatividade, capacidade de memorização, imaginação, prazer em ouvir, concentração, atenção e principalmente o senso crítico, que permite discutir os diferentes conteúdos abordados ao longo das canções (MOREIRA et. al, 2014). A utilização da música para ensinar resgata a sua função e verdadeiro valor como elemento auxiliar na formação do indivíduo, a partir do momento que passa a ser uma importante alternativa para estreitar o diálogo entre os alunos, professores e o conhecimento científico, uma vez que abordam temáticas com grande potencial de problematização (BRANDÃO e BARROS, 2016). Por fim, a música percorre o caminho de atividade prática, desviando o aluno das cansativas aulas expositivas, que não despertam grande interesse nos alunos, o que pode ocasionar a falta de atenção e consequentemente o baixo rendimento escolar. 


\section{REFERÊNCIAS}

ABREU, Zequinha. Tico-tico no fubá. Intérprete: Leci Brandão. In: Disney Adventures in Samba. Walt Disney Records, 2010. 1 CD. Faixa 3.

ABUD, K. M. Registro e representação do cotidiano: a música popular na aula de História. Cadernos CEDES. Campinas (SP), v. 25, n. 67, p. 309-317. Set/Dez. 2005.

BARROS M. D. M; DINIZ P. G. Z; ARAUJO-JORGE T. C. A música “O mundo é um moinho” como estratégia pedagógica para o ensino do tema transversal orientação sexual na escola... proposta e algumas considerações. Revista Práxis. Volta Redonda (RJ), Ano VIII, n. 15, p.37-41, junho de 2016.

;___________ Descobrindo ciências em letras de músicas 1- Ciência e Arte em oficinas dialógicas de música. Com Ciência e Arte na Escola@ LITEB/IOC/Fiocruz, Rio de Janeiro, 8p, 2014a.

; ___ _ _ _ Descobrindo ciências em letras de músicas 2- Brasil sem Miséria em oficinas dialógicas de música. Com Ciência e Arte na Escola@ LITEB/IOC/Fiocruz, Rio de Janeiro, 10p, 2014b.

; ZANELLA, P. G.; ARAÚJO-JORGE, T. C. A música pode ser uma estratégia para o ensino de ciências naturais? Analisando concepções de professores da educação básica. Revista Ensaio, Belo Horizonte, v.15, n. 01, p. 81-94, jan-abr., 2013.

BELISÁRIO, R.; STARLING, M. F. V.; ZANELLA, P. G., BARROS, M. D. M. Discutindo a revolução dos cravos nos contextos da botânica e da história na educação básica, a partir da música “Tanto Mar”, de Chico Buarque (1978). In: 64 Congresso Nacional de Botânica, Belo Horizonte, 10-15 de Novembro de 2013.

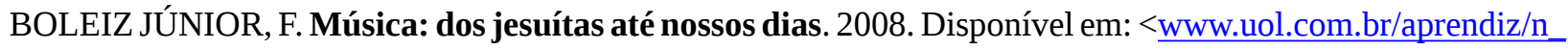
colunas/coluna_livre/id061201.htm>. Acesso em: 8 jun. 2015.

BRANDÃO, L. E. D.; BARROS, M. D. M. A utilização da música “Aqui no mar” como estratégia pedagógica para o ensino de Ciências e Biologia. European Review of Artistic Studies, Universidade de Trás os Montes e Alto Douro (Portugal). v. 7, n. 1, p. 1-20. 2016. ISSN 1647-3558.

BRANDÃO, L. E. D.; BELISÁRIO, R.; RODRIGUES, H. T. S.; STARLING, M. F. V.; ZANELLA, P. G.; BARROS, M. D. M. A utilização da música “Espatódea” como estratégia para o ensino de botânica: aproximações com o ensino de Ciências e Biologia. 66 $^{\circ}$ Congresso Nacional de Botânica, 2015. Livro de resumos do $66^{\circ}$ Congresso Nacional de Botânica, 2016. v. único, p. 485-485.

BRANDÃO, L. E. D.; BELISÁRIO, R.; RODRIGUES, H. T. S.; STARLING, M. F. V.; ZANELLA, P. G.; BARROS, M. D. M. Ensinando botânica a partir da música Feira de Mangaio de Sivuca e Glorinha Gadelha (1979). In: XI Congreso Latinoamericano de Botánica /LXV Congresso Nacional de Botânica, 2014, Salvador. XI Congreso Latinoamericano de Botánica - Botânica na América Latina: conhecimento, interação e difusão, 2014.

BUARQUE, C. Tanto mar. 1978. Intérprete: Chico Buarque. Chico Buarque. São Paulo: PHILIPS. Faixa 10. $1 \mathrm{CD}$.

DIAS, João. Tico-tico. Disponível em: <http://www.wikiaves.com.br/tico-tico> $>$. Acesso em: 24 mar. 2015.

FARIAS, Erick. Espantalhos. Rio Grande do Norte: 2010. Disponível em: < http://misteriosfantasticos.blogspot. com.br/2010/10/espantalhos.html>. Acesso em: 20 jun. 2015.

FERREIRA, M. Como usar a música na sala de aula. 7. ed. São Paulo: Contexto, 2008. 
GIASSI, M. G.; MORAES, E. C. A contextualização no Ensino de Biologia: abordagens preliminares. In: Anais do VI ENPEC - Encontro Nacional de Pesquisa em Educação e Ciências, Florianópolis, Santa Catarina, 26

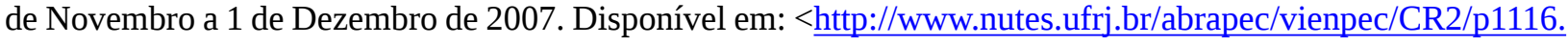
pdf>. Acesso em: 5 jan. 2015.

MARTINS, C. M. C.; TOLEDO, M. I. M.; SANTOS, M. B. L.; BRAGA, S. A. M. Proposta Curricular: Biologia do Ensino Médio. Minas Gerais: Secretaria de Estado de Educação, 2014.

MOREIRA, A. C.; SANTOS, H.; COELHO, I. S. A música na sala de aula: a música como recurso didático. UNISANTA Humanitas. Santos (SP). v. 3 n. 1, p. 41-61, 2014.

OLIVEIRA, Gabriel. Benefícios do alpiste. Disponível em: < $\underline{\text { http://www.remedio-caseiro.com/beneficios-do- }}$ alpiste/>. Acesso: 25 mar. 2015.

OLIVEIRA, S. D., GADELHA, G. Feira de Mangaio. Intérprete: Clara Nunes. "Esperança” (1979). EmiOdeon, 1979. 1 CD. Faixa 12.

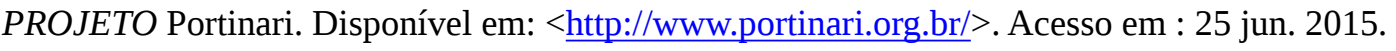

RUPPERT, Edward E., FOX, Richard S., BARNES, Robert D. Zoologia dos invertebrados. 7. ed. São Paulo: Roca, 2005.

SANTIAGO, Rodrigo Girardi. Tico-tico ou tico-tico-comum [Zonotrichia capensis]. [S.l.: s.n.], 2008. Disponível em: <http://dimaserose.blogspot.com.br/2008/06/tico-tico-ou-tico-tico-comum.html>. Acesso em: 25 jun. 2015.

SCHIEDECK, G.; SCHIAVON, G. A. Densidade e biomassa de minhocas em pomar de pessegueiro sob diferentes manejos do solo. Revista Brasileira de Agroecologia, Rio Grande do Sul, v.4, n.2, nov. 2009.

SILVA, K. F.; TEIXEIRA, X. T. A.; SPÓSITO, R. C. A.; MARISCO, G. A experimentação aplicada no ensino de biologia: contribuições na aprendizagem de microbiologia no ensino médio. In: V EREBIO - Encontro Regional de Ensino de Biologia, Universidade Federal do Rio Grande do Norte, Natal/RN, 2013. Disponível

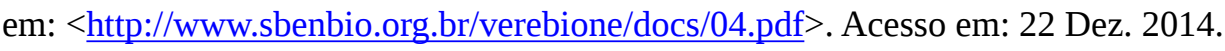

SILVA, R. P.; SANTOS, C. N. P.; FALCÃO, M. S.; LIRA, L. T. O.; ARAÚJO, M. L. F.; SOUZA, J. S. Ensino de Ciências e Biologia na escola pública: o que dizem os educandos de seu processo formativo. In: IX CONID - Congresso de Iniciação à Docência, 2009, RECIFE. IX - Jornada de Ensino, Pesquisa e Extensão, 2009.

SOBRINHO, R. S. A importância do Ensino da Biologia para o cotidiano. Monografia apresentada como requisito parcial para obtenção do título de Licenciado em Biologia no Programa Especial de Formações de Docentes da Faculdade Integrada da Grande Fortaleza, Fortaleza - CE, 2009.

STEFFEN, G. P. K., ANTONIOLLI, Z. I., STEFFEN, R. B., JACQUES, R. J. S. Importância ecológica e ambiental das minhocas. Revista de Ciências Agrárias [online]. v. 36, n. 2, p. 137-147. 2013.

UZUNIAN, A. BIRNER, E. Biologia volume único. 3 ed. São Paulo: Editora HARBRA, 2008. 1201p. 